\title{
Determinants of Maternal Health Care Utilization in Nepal
}

Renuka Kumari Karki (M. Phil.)*

\section{Abstract}

This study aims to analyze the determinants of maternal health care utilization in Nepal. Maternal health still remains a public health problem in Nepal though it has been improving in the last decade since the number of women seeking antenatal care and opting for institutional delivery has increased. This study is based on Nepal Demographic and Health Survey data of 2016. The sample size consists of 3998 married women aged 15-49 years who had a live birth in the five years preceding the survey. Bivariate analysis is used to examine the association between adequate ANC visits and institutional delivery. A strong association is observed between women's higher level of education and women involved in non-agricultural occupation with receipt of antenatal care and choosing of institutional delivery. The study findings conclude that there is a significant gap among different sub-groups of women in Nepal in the utilization maternal health care based on factors like women's age, place of residence, level of education, occupation and wealth status. In order to address the existing gap and variation in ANC service utilization, particular attention should be given to women from less education, poor wealth quintile, living in rural areas, utilization of services among older age group. The results of this study put forward the need for efforts from government bodies and agencies in implementation of appropriate policies and programs to bring an improvement in the use of maternal health care services in Nepal.

Key words: Maternal health, antenatal visit, institutional delivery, determinants \& utilization.

\section{Introduction}

Maternal mortality remains a major public health concern worldwide, especially in developing countries, hence it is mention in the top 5 millennium development goals (MDGs) and in sustainable developmental goals (SDGs). Globally, approximately 810 women die every day from pregnancy or childbirth related complications and approximately

\footnotetext{
${ }^{\star}$ Ms. Karki is a Lecturer at the Department of Population Studies, Patan Multiple Campus, TU, Lalitpur, Nepal.Email: bogatirenu7@gmail.com
} 
6,700 newborn deaths every day around the world (World Health Organization, 2019). Maternal mortality in Nepal is still high 239 per 10,0000 live births. One woman in 167 can be expected to have a maternal death while age 15 to 49 . The Government aims to reduce the maternal mortality ratio to 70 per 100,000 live births and neonatal mortality to 12 per 1,000 live births and to achieve coverage of 90 percent for four ANC visits, institutional delivery, SBA delivery, and three PNC check-ups by 2030 as part of the SDGs target. Still, the proportion of women utilizing maternal health services is low in Nepal. Nationally, 69 percent of women had at least four ANC visits and only 57 percent of births were delivered in the health facilities (Ministry of Health and Population, 2017).

Maternal health refers to the health of the women during pregnancy, childbirth and the postpartum period, therefore, maternal health service includes antenatal care (ANC), delivery care and postnatal care (PNC). The lives of millions of women of reproductive age can be saved through proper utilization of maternal health care services. Antenatal care (ANC) is an important component of maternal health which helps to identify the complications and potential risks during pregnancy and also helps to plan a safe delivery. Antenatal care provides the opportunities to encourage women to deliver with the skilled birth attendants (Mrisho et al., 2009). World Health Organization (WHO) has recommended women to attend at least four ANC visits during their pregnancy. Antenatal care from a trained provider is important in order to monitor the risks associated with pregnancy, delivery for the mother and her child. Health care service during pregnancy and childbirth and after delivery are important for the survival and well-being of both the mother and the neonate. The antenatal care is an entry point for maternal and child healthcare service utilization through which pregnancy risk can be detected and managed and contributes to reducing both the maternal and neonatal mortality (Dahiru, \& Oche, 2015). During ANC visits, women are given the health education on the health of mother and child which facilitates them in making a decision for skilled attendance or institutional delivery. It is found that women who utilized ANC services are more likely to utilize skilled attendance at delivery or institutional delivery (Pervin et al., 2012).

Similarly, the second component of maternal health care services, institutional delivery, allows detection and management of risk during labor and childbirth so that effective interventions can be provided by medically trained personnel at a health facility (Hatt et al., 2009). Institutional delivery service is one of the key and proven interventions to reduce maternal death. It ensures safe birth, reduce both actual and potential complications and maternal death and increase the survival of most mothers and newborns (Yarinbab \& Balcha, 2018). Thus, this study intends to fill this gap and contribute to the understanding of women's demographic and socio-economic variables on the use of antenatal care service and delivery care. 
In Nepal maternal health is one of the national priorities and improving maternal health is a major focus of the current national development plan. The government of Nepal is promoting safe motherhood programs through various initiatives such as providing free delivery care and transportation incentives to women delivering in a health facility (MoHP, 2017). The government of Nepal initiated the free delivery care services in 2005 through the 'Maternal Incentive Scheme' to increase health facility delivery. In 2009, the scheme was expanded to include 'free deliveries' and in the same year, the government of Nepal introduced the "four ANC incentive program" to improve ANC attendance (Bhatt et al., 2018). Despite the need and the efforts made by the government of Nepal through different policies to improve access to maternal health care services and reduce maternal mortality, complete maternal health service utilization has been very limited. Considering the importance of maternal health, this study has examined the antenatal care and delivery care of mothers in Nepal. Data has been analyzed according to the different background characteristics such as mother's age at birth, place of residence, occupation, education level, and wealth quintile.

\section{Objectives of the Study}

The main objective of this study is to analyze the determinant of maternal health care utilization in Nepal. The specific objective is as follows:

- To examine the relationship between demographic and socio-economic variables and the utilization of antenatal care and delivery care services in Nepal.

\section{Methodology}

Nepal Demographic and Health Survey (NDHS) 2016 data set is utilized for the study. This is a nationally representative survey and is the fifth survey carried out in Nepal. The study population for this analysis is 3998 married women aged 15-49 years who had a live birth in the five years preceding the survey. In this study, the adequate ANC visit and institutional delivery are employed as dependent variables. In this study, ANC visit is a dependent variable (outcome variables) which is categorized as 'adequate ANC visit' for women who attend the 4 or more ANC visits and "inadequate ANC visit" for the women who attend less than four or no antenatal care visits. "Place of delivery" is taken as a dependent variable. Place of delivery is further dichotomized as home delivery (for the birth that took place at home) and institutional delivery (for the birth that took place at a hospital or primary health care center or a health facility). This study is analyzed independent variables in terms of women's demographic, socio-economic characteristics in this study. This study is analyzed using cross tabulation to understand the distribution 
of different independent variables with respect to outcome variables. Bivariate analysis is used to examine the association between adequate ANC visits and institutional delivery.

\section{Results and Discussion}

In this study, two main variables are used to analyze the utilization of maternal health care; adequate antenatal care and institutional delivery. The data shows that nearly 35 percent of women were aged 20-29 years at the time of the birth of their most recent child while 49 percent and 64 percent had no education and primary education respectively. While talking about place of residence, about 75 percent women were from urban area and 62 percent were from rural area. A higher 84 percent of women who received antenatal had secondary and higher education. Result shows that only 31 percent of mothers has made adequate visit for their most recent birth (Table1). A large proportion that is 70 percent of the mothers did not make adequate antenatal visit. Only 61 percent of women had delivered in the institution.

Table 1: Percent distribution of respondents by background characteristics, 2016

\begin{tabular}{|l|c|c|}
\hline Background Characteristics & Number & Percent \\
\hline Mother Age at Birth & & 8.4 \\
\hline $15-19$ & 335 & 31.8 \\
\hline $20-24$ & 1271 & 34.5 \\
\hline $25-29$ & 1380 & 16.3 \\
\hline $30-34$ & 653 & 6.2 \\
\hline $35-39$ & 249 & 2.3 \\
\hline $40-44$ & 90 & 0.5 \\
\hline $45-49$ & 19 & \\
\hline Place of Residence & & 55.6 \\
\hline Urban & 75.4 & 44.4 \\
\hline Rural & 61.7 & \\
\hline Education Level & & 31.4 \\
\hline No education & 49.4 & 19.4 \\
\hline Primary & 64.1 & 49.1 \\
\hline Secondary and higher & 84.2 & \\
\hline Occupation of Women & & \\
\hline
\end{tabular}




\begin{tabular}{|l|c|c|}
\hline Not working & 1549 & 38.7 \\
\hline Not agriculture & 611 & 15.3 \\
\hline Agriculture & 1839 & 46.0 \\
\hline Wealth Quintile & & \\
\hline Poorest & 821 & 20.6 \\
\hline Poorer & 840 & 21.0 \\
\hline Middle & 863 & 21.6 \\
\hline Richer & 830 & 20.8 \\
\hline Richest & 643 & 16.1 \\
\hline Total & $\mathbf{3 9 9 8}$ & $\mathbf{1 0 0 . 0}$ \\
\hline
\end{tabular}

Source: Dataset of NDHS, 2016

- Weights are applied. The total might not equal to 100.0 as a result of rounding off cases.

About 46 percent of women were engaged in agriculture and only 15 percent in nonagriculture. Similarly, about 41.6 percent of women were from poor wealth status and 36.9 percent of women belonged to rich status (Table 1).

Table 2: Percent distribution of respondents by the antenatal visits and the place of delivery, 2016

\begin{tabular}{|l|c|c|}
\hline Variables & Number & Percent \\
\hline ANC Visit & 1225 & 30.6 \\
\hline Adequate & 2773 & 69.4 \\
\hline Inadequate & 1575 & 39.4 \\
\hline Place of Delivery & 2423 & 60.6 \\
\hline Home delivery &
\end{tabular}

Source: Dataset of NDHS, 2016

Results shows that only 31 percent of mothers have made adequate visit for their most recent birth (Table 2). Only 61 percent of women had delivered in the institution. Still two-fifth of delivery take place at home.

Significant differences were observed in utilization of maternal health care by socioeconomic and demographic characteristics (Table 3). The age of mother affects the use of ANC services. It is observed that the largest group of women who had adequate ANC 
visits was of age group 15-19, 20-24 and 25-29 years. The adequate ANC visits were higher in women of age group 15-19 than in women aged 45-49 i.e., 75 percent and 32 percent respectively. This result indicates that younger mothers received adequate ANC visits than older mothers. Similarly, about 75 percent of women living in urban areas reported receiving adequate $\mathrm{ANC}$ visits compared with 62 percent in rural areas.

Table 3: Percentage distribution of women who had a live birth in the five years preceding the survey by adequate ANC visit and institutional delivery for more recent live birth according to background characteristics, 2016

\begin{tabular}{|c|c|c|c|c|}
\hline \multirow[b]{2}{*}{$\begin{array}{l}\text { Background } \\
\text { Characteristics }\end{array}$} & \multicolumn{2}{|c|}{ Adequate ANC visit } & \multicolumn{2}{|c|}{ Institutional delivery } \\
\hline & Percent & $\begin{array}{c}\text { P-value } \\
\text { (Chi-square } \\
\text { test) }\end{array}$ & Percent & $\begin{array}{c}\text { P-value } \\
\text { (Chi-square test) }\end{array}$ \\
\hline \multicolumn{5}{|l|}{ Mother Age at Birth } \\
\hline $15-19$ & 72.8 & $<0.001$ & 70.4 & $<0.001$ \\
\hline $20-24$ & 71.4 & & 64.9 & \\
\hline $25-29$ & 70.7 & & 60.1 & \\
\hline $30-34$ & 68.3 & & 55.6 & \\
\hline $35-39$ & 61.4 & & 50.4 & \\
\hline $40-44$ & 44.4 & & 45.6 & \\
\hline $45-49$ & 31.6 & & 5.3 & \\
\hline \multicolumn{5}{|l|}{ Place of Residence } \\
\hline Urban & 75.4 & $<0.001$ & 71.3 & $<0.001$ \\
\hline Rural & 61.7 & & 47.2 & \\
\hline \multicolumn{5}{|l|}{ Education Level } \\
\hline No education & 49.4 & & 38.5 & \\
\hline Primary & 64.1 & & 50.9 & \\
\hline Secondary and higher & 84.2 & & 78.6 & \\
\hline \multicolumn{5}{|l|}{ Occupation of Women } \\
\hline Not working & 67.6 & $<0.001$ & 65.5 & $<0.001$ \\
\hline Not agriculture & 78.9 & & 75.9 & \\
\hline
\end{tabular}




\begin{tabular}{|l|l|l|l|l|}
\hline Agriculture & 67.7 & \multicolumn{3}{l|}{} \\
\hline Wealth Quintile & \multicolumn{5}{l|}{51.4} & \\
\hline Poorest & 56.7 & $<0.001$ & 36.5 & $<0.001$ \\
\hline Poorer & 65.4 & & 49.9 & \\
\hline Middle & 66.7 & & 61.3 & \\
\hline Richer & 74.7 & & 71.2 & \\
\hline Richest & 87.4 & & 91.8 & \\
\hline Total & $\mathbf{6 9 . 4}$ & & $\mathbf{6 0 . 6}$ & \\
\hline
\end{tabular}

Source: Dataset of NDHS, 2016

*Significant at $\mathrm{P}<0.001 ; * *=\mathrm{P}<0.01$ and $*=\mathrm{P}<0.05$

The results show that an increase in educational levels lead to a significant increase in the use of antenatal care services. For example, nearly 49 percent of mothers with no education make adequate ANC visit and higher percentage of women 84 percent with secondary education have made adequate ANC visit. Seventy-nine percent of mother who were engaged in non-agriculture occupation were made required number of ANC visits, whereas, it was only about 67.6 percent for not working mothers. Therefore, the strong association of women's level of education and women involved in non-agricultural occupation with receipt of antenatal care. Adequate ANC visits increases with increasing level of wealth index. The proportion of institutional delivery was the highest $(73 \%)$ in age group of 15-19 and lowest (32\%) in age group 45-49. In terms of education, approximately 85 percent of women who had secondary or higher levels of education had chosen institution delivery. Likewise, regarding the wealth index, nearly 68 percent of women from the middle category and about 87 percent of women who were from the rich category had delivered in the institution. As the level of wealth increased, the percentage of women with health facility delivery also increased. Overall results indicates that younger, educated, urban women, rich category women tend to deliver in the institution than older, uneducated, poor women. Antenatal care and delivery care respectively was observed with $\mathrm{P}$ value $<0.001$ indicates that there was high significant association between maternal health care services and socio-economic and demographic status.

\section{Conclusion}

This study examines the socio-demographic factors which are significant to determine the degree of maternal health care utilization in Nepal. The utilization of maternal healthcare services among women of reproductive age in Nepal is still inadequate. The percentage of 
women who seek adequate ANC visit is low. Still two fifth percent of delivery takes place at home. The results indicate that an increase in educational levels lead to a significant increase in the use of antenatal care and institutional delivery. Therefore, special emphasis on women's education plays a vital role to increase the utilization maternal health care. The study indicates that antenatal care is much more common for births to younger women than older. Urban women are more likely than rural woman to receive antenatal care and delivery care. This study reveals that large variation and gaps exits among women in Nepal in the utilization of antenatal care visits and institutional delivery service. Several demographic and socio-economic factors like women's age, place of residence, levels of education, occupation and wealth status has significantly influenced women for the utilization of antenatal care and institutional delivery facility. Thus, it is crucial to optimize the utilization of ANC services and institutional delivery service by addressing existing gaps among currently married women. To achieve the goals of universal health coverage, focus should be given to women from poor economic and social status, those with less education, living in rural areas and utilization of services among older age group should be encouraged.

\section{References}

Bhatt, H., Tiwari, S., Ensor, T., Ghimire, D. R., \& Gavidia, T. (2018). Contribution of Nepal's free delivery care policies in improving utilization of maternal health services. International Journal of Health Policy and Management, 7(7).

Dahiru, T., \& Oche, O. M. (2015). Determinants of antenatal care, institutional delivery and postnatal care services utilization in Nigeria. The Pan African Medical Journal, 21. DOI: $10.11604 /$ pamj.2015.21.321.6527

Hatt, L., Stanton, C., Ronsmans, C., Makowiecka, K., \& Adisasmita, A. (2009). Did professional attendance at home births improve early neonatal survival in Indonesia? Health Policy and Planning, 24(4).

Ministry of Health and Population (MoHP). (2007). Nepal demographic and health survey 2006. Kathmandu: Ministry of Health and Population New ERA and IFC International, Nepal.

Ministry of Health and Population (MoHP). (2012). Nepal demographic and health survey 2011. Kathmandu: Ministry of Health and Population New ERA and IFC International, Nepal.

Ministry of Health and Population (MoHP). (2017). Nepal demographic and health survey 2016. Kathmandu: Ministry of Health and Population New ERA and IFC International, Nepal. 
Mrisho, M., Obrist, B., Schellenberg, J. A., Haws, R. A., Mushi, A.K., Mshinda, H., Tanner, M., \& Schellenberg, D. (2009). The use of antenatal and postnatal care: Perspectives and experiences of women and health care providers in rural southern Tanzania. BMC Pregnancy and Childbirth, 9(10).

Pervin, J., Moran, A., Rahman, M., Razzaque,A., Sibley, L., Streatfield, P. K., Reichenbach, L. J., Koblinsky, M., Hruschka, D., \& Rahman, A. (2012). Association of antenatal care with facility delivery and perinatal survival: A population based study in Bangladesh. BMC Pregnancy Childbirth, 12(111). https://doi.org/10.1186/14712393-12-111

World Health Organization (WHO). (2019). Trends in maternal mortality 2000 to 2017: Estimates by WHO, UNICEF, UNFPA, World Bank Group and the United Nations Population Division: Execute summary. https://apps.who.int/iris/ handle/10665/327596

Yarinbab, T. E., \& Balcha, S. G. (2018). Delays in utilization of institutional delivery service and its determinants in Yem special Woreda, Southwest Ethiopia: Health institution based cross-sectional study. Journal of Gynecology Women's Health, 10(3). 